\title{
GROUND BASED 3D MODELLING (PHOTOGRAMMETRY AND TLS) - SURVEY, DOCUMENTATION AND STRUCTURAL ASSESSMENT OF XX CENTURY CULTURAL HERITAGE IN INDIA - A CASE STUDY OF THE MASONRY VAULTS IN DEHRADUN
}

\author{
G. Tucci ${ }^{1}$, S. Rihal ${ }^{2}$, M. Betti ${ }^{1}$, A. Conti ${ }^{1}$, L. Fiorini ${ }^{1}$, , V. C. Kovacevic ${ }^{1}$, G. Bartoli ${ }^{1}$ \\ ${ }^{1}$ Dept. of Civil and Environmental Engineering, University of Florence, via Santa Marta 3, Florence, Italy \\ grazia.tucci@unifi.it, mbetti@dicea.unifi.it, arch.a.conti@gmail.com, \\ lidia.fiorini@gmail.com, vladimir.kovacevic@kobe-ie.com, gianni.bartoli@unifi.it \\ ${ }^{2}$ College of Architecture \& Environmental Design, Cal Poly State University, San Luis Obispo, California, U.S.A. \\ sat.rihal@gmail.com
}

KEY WORDS: Masonry vaults, Structural assessment, C.G. Blomfield, FEM, Educational, Capacity Building Initiative, TLS.

\begin{abstract}
:
The paper presents the case study of the survey of the sail vaults of the main building of the Forest Research Institute in Dehradun. The building has been acquired with photogrammetric and laser scanner techniques during the Ground Based 3D Modelling (Photogrammetry and TLS) tutorial, at the ISPRS TC V Mid-term Symposium held in Dehradun, India in November 2018. The acquired data was then used for a structural evaluation of masonry vaults. The 3D model, built using the point cloud data, has been used in an open source finite element analysis software to develop a numerical model and comparative analyses have been carried out. The objective of numerical analysis is assessing both the benefits of structural meshes generated directly from point cloud data and the structural behaviour of the masonry vaults.
\end{abstract}

\section{AIMS AND OBJECTIVES}

The paper presents the case study of the survey of a portion of the main building of the Forest Research Institute in Dehradun carried out as a training activity during the 'Ground Based 3D Modelling (Photogrammetry and TLS)' Tutorial, at the ISPRS TC V Mid-term Symposium, held in Dehradun, India in November 2018.

After a brief introduction to the history and architectural characteristics of the building, the activities carried out in the acquisition phase, the vaulting modelling tests, the geometrical analyses and the results of the FE analyses carried out starting from the point cloud model are discussed.

\section{THE FOREST RESEARCH INSTITUTE DEHRADUN: HISTORY AND ARCHITECTURE}

Founded as Imperial Forest Research Institute in 1906, Forest Research Institute (FRI) Dehradun, is one of the main institutions of the Indian Council of Forest Research and Education (ICFRE). The main building inaugurated in 1929 was designed by the English architect Charles George Blomfield, a pupil of Sir Edwin Lutyens. This impressive neoclassical architecture is located within a vast area of lush greenery, often visited by tourists and locals as a place for recreation and relaxation. The two-storey building has an elongated rectangular plan with the longer side (about $300 \mathrm{~m}$ ) is about 3 times longer the other. The pavilion roof has a dark stone coating. The central part of the building is rearward forming an open courtyard, on which stands the main entrance with a double-height portico with columns and a barrel vault. The corners of the courtyard are highlighted by two octagonal towers covered by domes. The building contains six courtyards and all the external facades, except the rear one and all the internal ones overlooking the courtyards have two-level arcades with the ground floor with vaulted ceilings. This solution, typical of colonial architecture provides indirect illumination of the adjacent rooms, better air circulation and protection from rain. (Tillotson, 2008).

The building is entirely built with red bricks. As architect C.G. Blomfield was unable to use steel because it was too expensive, he was obliged to use local materials and workers, but he managed to transform the necessity into an expressive form (Figure 1). The architect doubted the building skills of local workers except in the construction of the vaults, which had been part of the local building tradition for thousands of years.

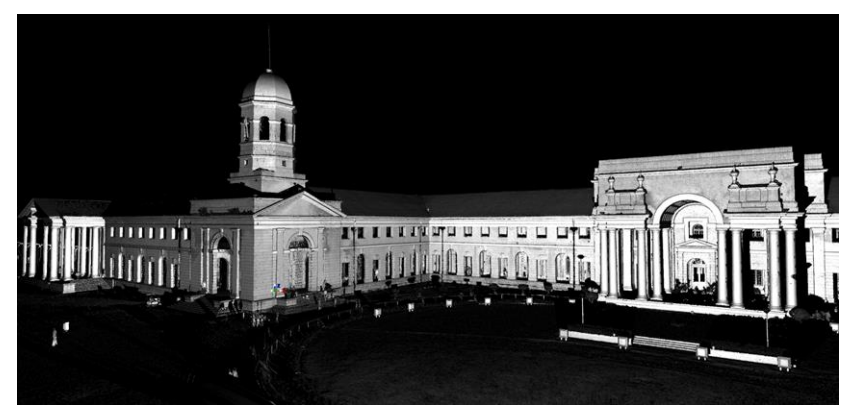

Figure 1. Forest Research Institute 3D model point clouds.

The bricks are used on the exterior facades for simulating ashlars and for building the pilasters and the lintels of the arches. The module of the brick establishes the proportions of the architectural elements, and the brickwork is laid in the English bond. The joints, pointed with white mortar, increase the sense of horizontality of the building. In particular, the vaults examined for this paper show tuckpointed joints that at

\footnotetext{
* Corresponding author
} 
the top of the vaults do not follow the real masonry texture but sometimes simulate a brickwork more regular than the real one (Figure 2).

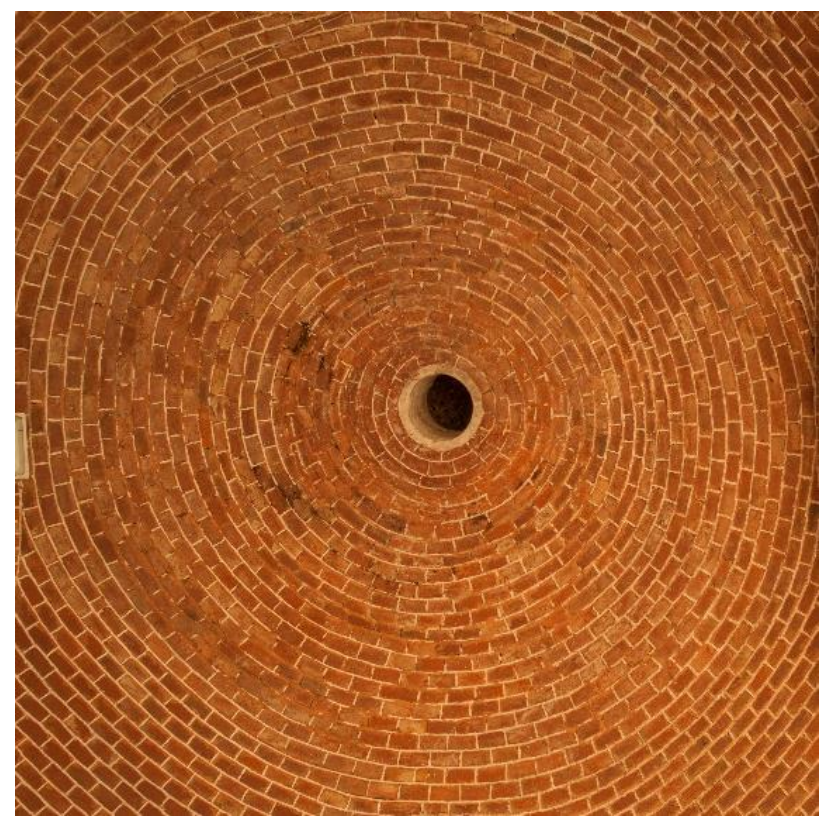

Figure 2. The masonry texture of the sail vaults.

\section{THE SURVEY}

\subsection{The tutorial}

The Ground Based 3D Modeling (Photogrammetry and TLS) tutorial was held during the ISPRS TC V Mid-term Symposium in Dehradun, India in November 2018. The tutorial was one of the steps planned within the project "Educational and training resources on digital photogrammetry", funded in 2018 by ISPRS under the "Educational and Capacity Building Initiative" (Tucci et al., 2018a). The programme envisaged carrying out some on-the-field activities aimed at digitizing a significant case study, both by laser scanning and digital photogrammetry, to allow data comparison and a critical overview of both processes. The laser scanner point model, considered as reference for further tests, and a set of images and ground control points as well made available online, as "reference data set" for practicing with photogrammetric software and supporting educational initiatives.

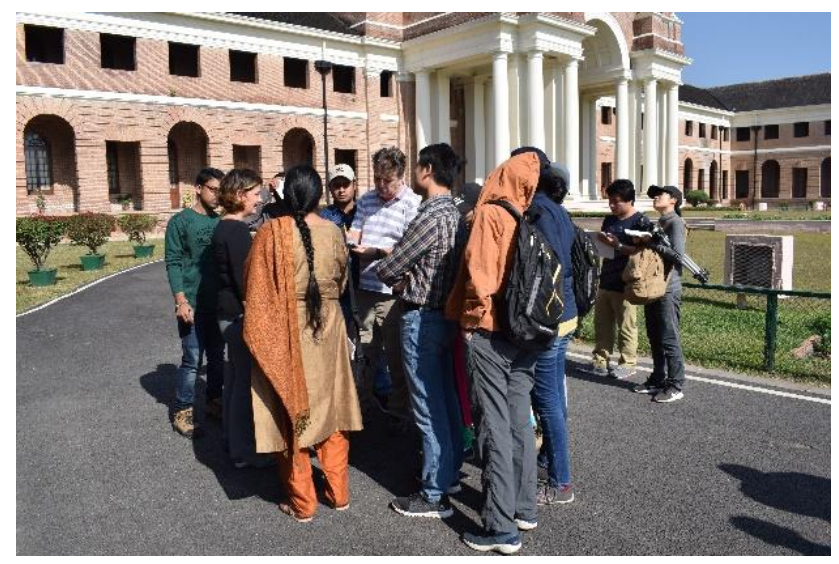

Figure 3. Field work in Progress.
Tutorials and workshops are useful to the participants as training events and are an opportunity to collaborate in the documentation and protection of the local cultural heritage (Tucci et al., 2012; Cardinale et al., 2013; Achille et al., 2018).

The three-dimensional data collected during these training experiences, especially if repeated regularly over time, contribute to the creation of three-dimensional databases that can be provided and used by cultural heritage institutions (Municipalities, Administrations, Museums, etc.). In turn, they can support educational events by creating a virtuous circle of good practices (Fiorillo et al., 2013)

Another aim of these initiatives is essentially social: the active participation of people in projects for cataloguing and documentation of local built heritage, also facilitates the construction of the social capital. The participation in cultural heritage events, highlighting the authenticity and uniqueness of its heritage, strengthens the awareness of the community and helps to develop a sense of belonging and to feel themselves as an active part of its safeguard (Tucci et al., 2018b).

\subsection{The survey field-work}

The tutorial has been attended by 15 students from many countries for deepening their knowledge and practice in the use of up-to-date reality-based 3D acquisition and modelling techniques. After a first day of theoretical introduction to 3D acquisition techniques, the second day was spent on field-work and finally during the third day the acquired data was processed (Figure 3).

During the tutorial, after a careful analysis of the location, the students, supported by the tutors, designed the positioning of the laser scanner stations and targets useful for the alignment of the scans. Due to the shortage of time, the aim of the field experience was to document the facades of the central court only, with a special attention to the left wing, where the vaulted portico at the ground floor has been surveyed. Ten targets were positioned on the scene and 14 scans were made with a highspeed phase-based 3D laser scanner. Seven scans were made with the scanner positioned at the centre of the bay for every second vault in the loggia, to describe the nine bays and the corner spaces at the end of the wing. Another five scans were made along the facade, with the scanner at about ten metres from the facade.

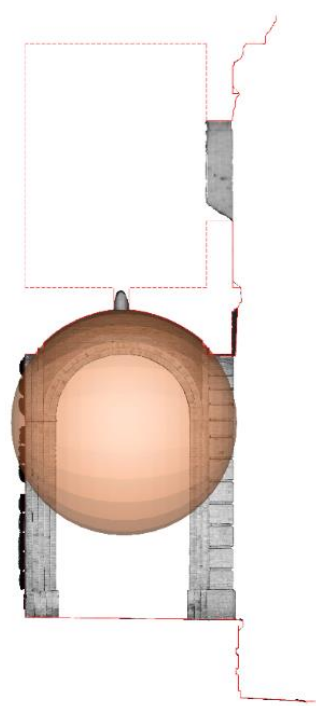

Figure 4. Schematic cross section showing the best fitting sphere to the vault. 
The resolution was set at $6 \mathrm{~mm}$ at $10 \mathrm{~m}$, because the building is about $12 \mathrm{~m}$ high and that the resolution chosen would have to be enough for a 1:50 scale drawing and for surface modelling. Finally, two more scans were made at a higher resolution from more distant points of view to acquire even the roof (Figure 4). As it was not possible to have access at the first floor, it has not been possible to directly measure the thickness of the floor between ground and first level. However, the presence of drainage holes at the top of the vault, the lack of window frames at the first floor of the loggia and partial data acquired from the courtyard still made it possible to assess the overall size of the space of the porch on the first floor.

The scans were made with only the reflectance values because the RGB value would have been acquired during the photogrammetric project that involved only the external facade and whose results are not described here. The laser scanner data were processed later in the classroom.

\section{MODELLING AND GEOMETRY ANALYSIS}

The most qualifying elements of the building are the vaulted ceilings that are set on two pillars and two pilasters on which rounded arches are set. Geometrically, the sail vaults consist of a spherical cap circumscribed in a square plan, consisting of the planes of the arches that delimit it. Constructively, the vaults under examination show a very regular texture in the portions up to the level of the key of the arches (the pendentives) and a less regular texture in the cap. The header bricks are arranged in concentric rings (Brumana et al., 2018; Balletti et al., 2018) (Figure 5).

From the point cloud model, the portion corresponding to two bays of the portico was extracted, one with a rounded arch (vault $\mathrm{A}$, with a hole at the top, where it is possible to measure the thickness of the floor) and one with a jack arch (vault B). A mesh model has been obtained from the selected portion to display the model.
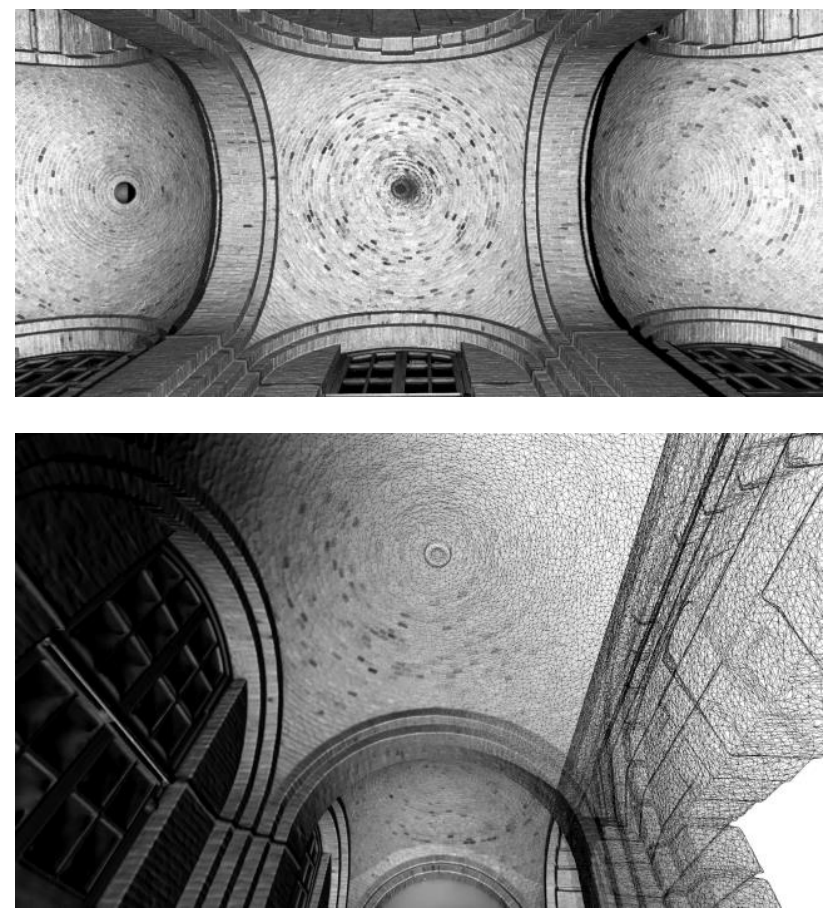

Figure 5. Mesh model vaults.
Another smaller portion of the point cloud was segmented, selecting only the two adjacent vaults. The RANSAC algorithm (Schanbel et al., 2007) in the implementation of the CloudCompare software (CloudCompare 2.10.2, 2019) was used to perform a best fit with geometric primitives as planes, spheres and cylinders

The two vaults were very regular, as the radius of the best fitting spheres is:

vault $\mathrm{A} \quad \mathrm{r}=2.074212 \mathrm{~m}$

vault B $\quad r=2.071445 \mathrm{~m}$

To evaluate the distance between the point cloud and the best fitting sphere, deviation maps were made using the $\mathrm{M} 3 \mathrm{C} 2$ algorithm, again in the CloudCompare software. The deviation between the vaults and the best fitting spheres is less than \pm 3 $\mathrm{cm}$ and can be justified within construction tolerances and irregularities.

It is possible to distinguish two parts on the vaults: from the impost up to the key of the side arches (i.e. in the area of the pendentives) there is a slight irregularity corresponding to the diagonals (more visible in the vault $\mathrm{A}$ ), justifiable more by the eccentricity of the construction ribs than by structural deformation.

Both the sail vaults then show a variation of curvature at the level of the key of the side arches, where the top of the vaults starts, where it is possible to see a circular shape in the deviation maps. The discontinuity is sometimes visible even at the site as a thin circular crack (Figure 6).
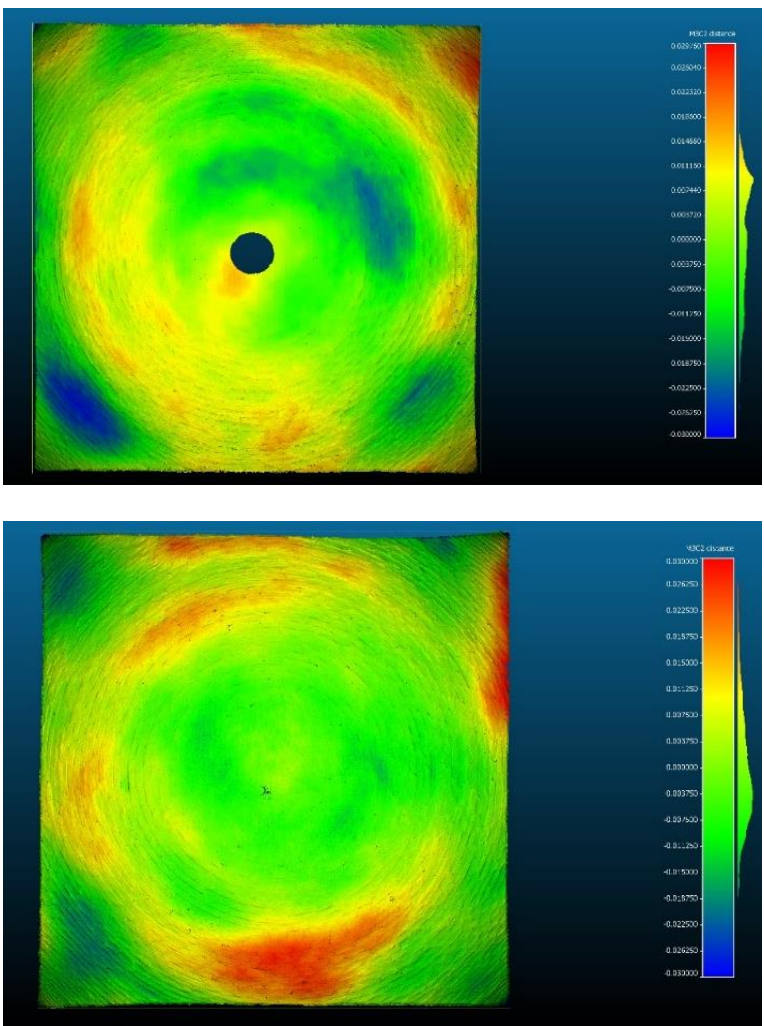

Figure 6. Deviation maps of the vault A (Up) and B (Down)

\section{STATIC VULNERABILITY OF THE VAULTED ELEMENTS}

Based on the TLS survey carried out on a portion of the building, it was possible to extract the geometry of the typical vaults which characterize the portico of the complex front-court (Figure 7). 


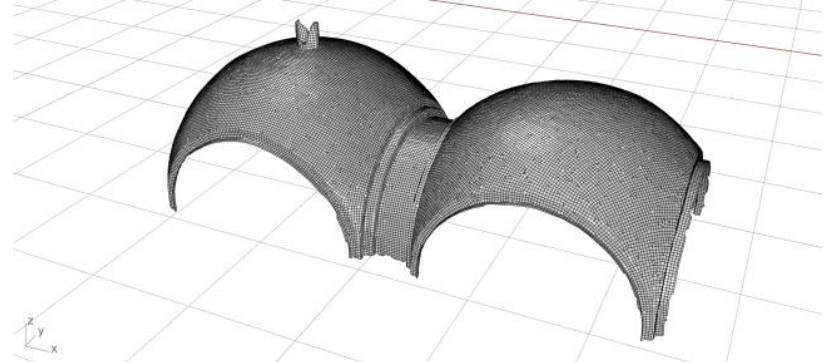

Figure 7. Intermediate phase of the vaulted elements mesh elaboration for FEM analysis

Specifically, the mesh derived from the point-cloud data was exploited to build a lower definition FEM compatible mesh (Korumaz et al., 2017), to be used for numerical analysis purposes.

Many parameters were supposed to be unknown, such as the elastic modulus of the masonry, the materials density (both for the vault and the buttress) and the vault thickness.

At the same time, an ideal geometrical model of the vaults, described by a perfectly spherical surface, was used to build other two FEM models, to be used for a comparison of the results. In synthesis, three FEM models were built:

a) $3 \mathrm{D}$ idealized geometry model, with volume finite elements;

b) 2D idealized geometry model, with shell finite elements;

c) $2 \mathrm{D}$ mesh derived from the point cloud data, with shell finite elements.

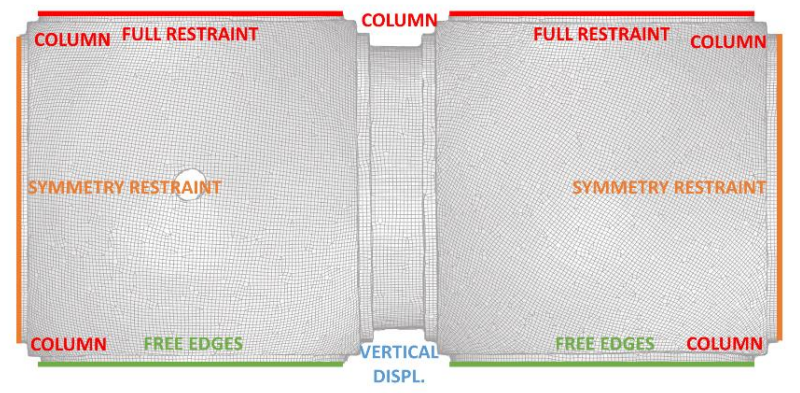

Figure 8. Boundary conditions of the vault.

The models were run inside the open source platform 'salome_meca' (Pieraccini et al., 2017 and Bartoli et al., 2017), assigning the correct boundary conditions (Figure 8), the exact distribution of the weights over the top vault surface and imposing a vertical displacement on the central column, a classic failure cause for masonry structures, in order to test i) the sensitivity of the input parameters on the results (maximum principal stress that will lead to cracking) and ii) the sensitivity of the non-linear behaviour for different types of modelling.

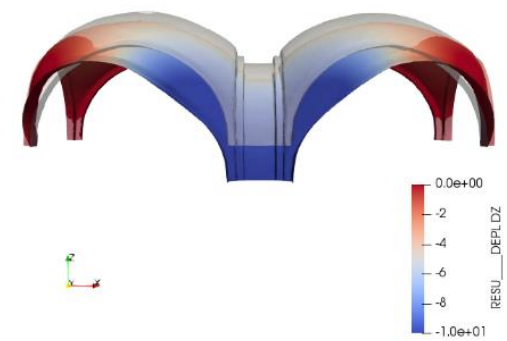

Figure 9. Imposed $10 \mathrm{~mm}$ displacement of the central column.

The displacement of the vault with the imposed $10 \mathrm{~mm}$ vertical displacement on the central column is reported in Figure 9 while the distribution of the maximum principal stresses in the extrados and the intrados is reported in Figure 10.

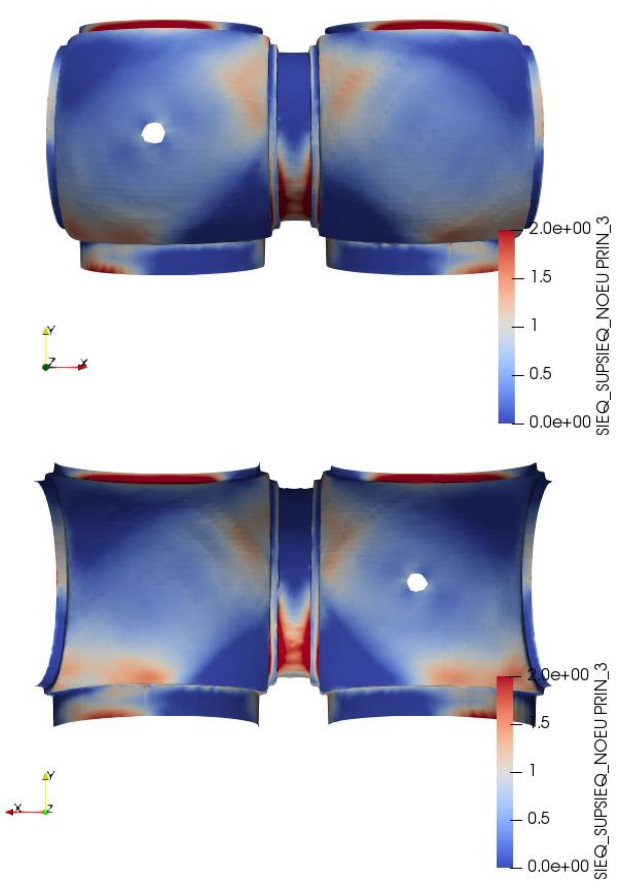

Figure 10. Distribution of the maximum principal stresses in the extrados and the intrados of the vault for an imposed $10 \mathrm{~mm}$ displacement of the central column.

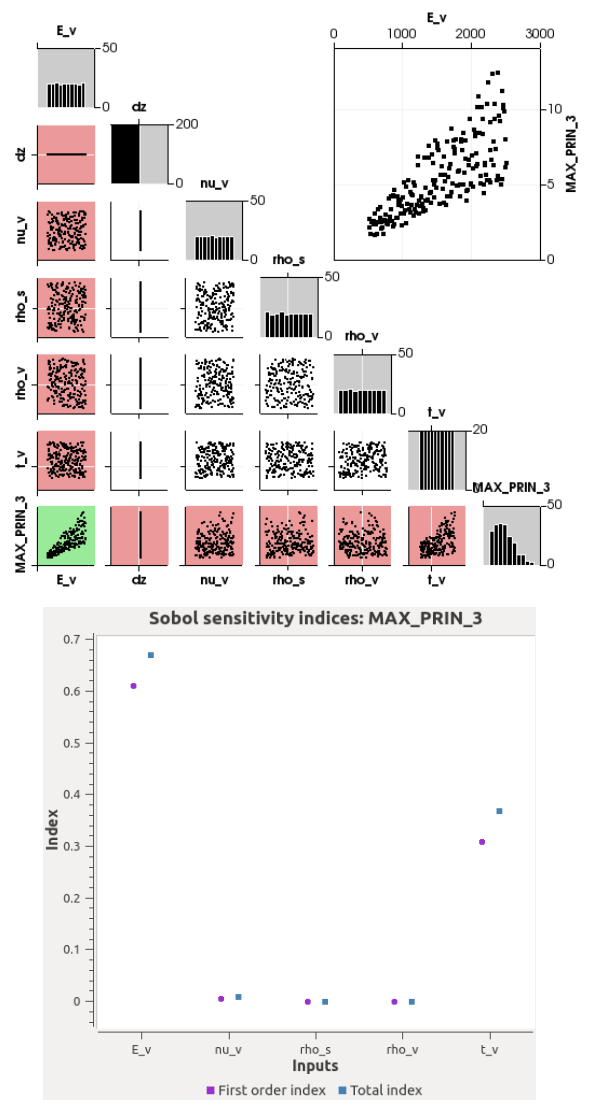

Figure 11. 200 LHS simulations for the middle layer maximum principal stress (the sensitivity, calculated with the Sobol indices, is reported below). 


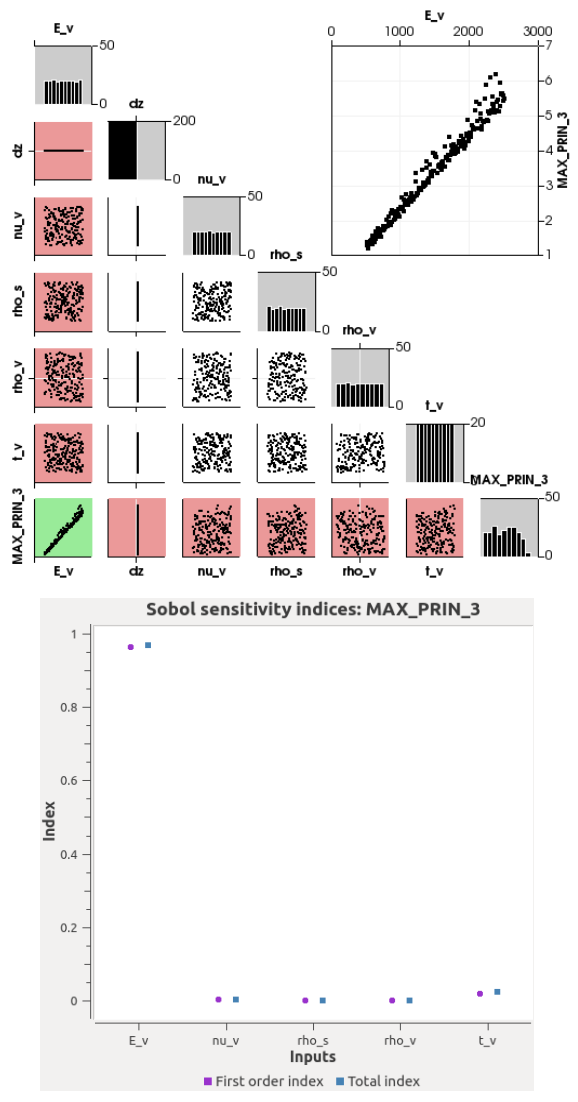

Figure 12. 200 LHS simulations for the top layer maximum principal stress (the sensitivity, calculated with the Sobol indices, is reported below).

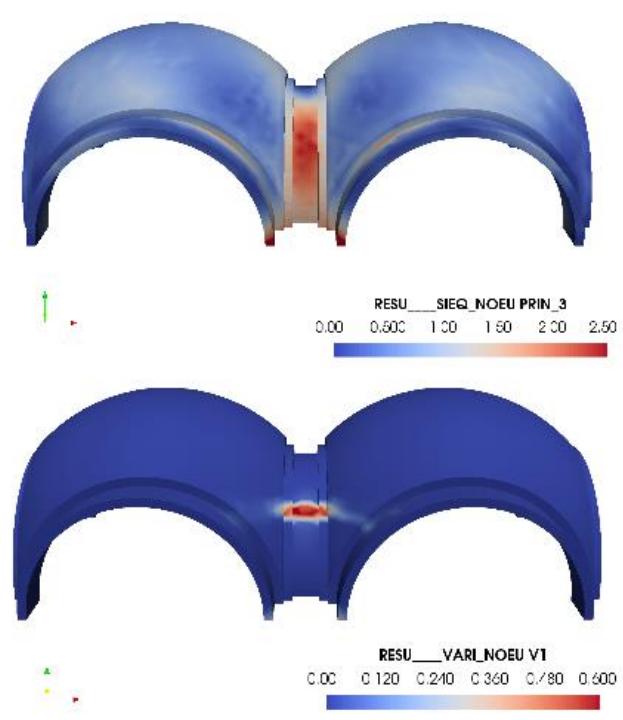

Figure 13. Analysis performed with the vertical displacement imposed on the central column on the 3D idealized geometry model: distribution of maximum principal stresses before cracking (Up) and the damage pattern (Down).

The sensitivity on the input parameters was tested through a parametric analysis of the model (c) (geometry derived from the cloud point data), based on a Latin Hypercube Sampling (LHS;
McKay, 1992) of 200 simulations, with two types of output: the principal stress on the middle layer and on the top layer.

The tested input parameters are the properties of the masonry (density, elastic modulus, Poisson's ratio), the density of the filling and the thickness of the vault. The analyses were performed with the OpenTURNS module inside the salome_meca ecosystem (Baudin et al., 2016).

Based on the results of the parametric LHS simulations (in Figure 11 and Figure 12), the major influence on the output, given by Sobol indices (Sobol, 1993), is exerted by the stiffness of the material, both for middle and top layer principal stresses. The thickness of the vault has a minor influence on the middle layer stresses.

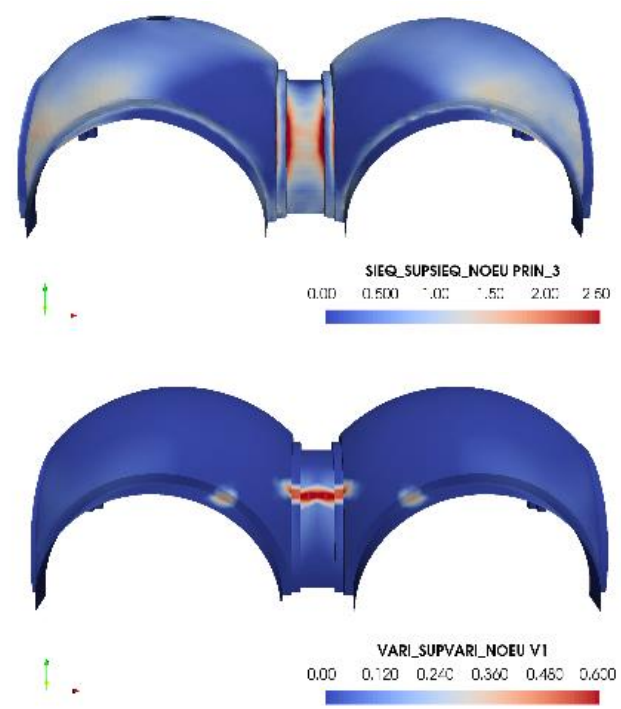

Figure 14. Analysis performed with the vertical displacement imposed on the central column on the 2D idealized geometry model: distribution of maximum principal stresses before cracking (Up) and the damage pattern (Down).

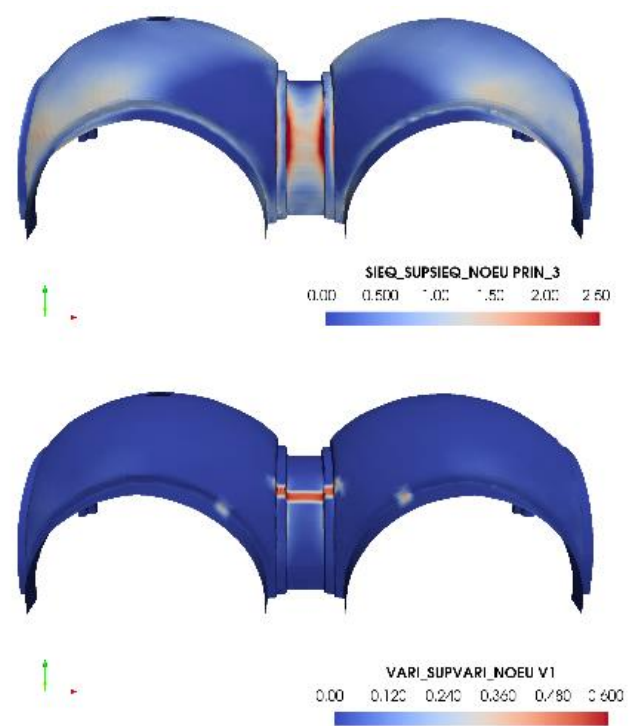

Figure 15. Analysis performed with the vertical displacement imposed on the central column on point cloud-derived 2D model: distribution of maximum principal stresses before cracking (Up) and the damage pattern (Down). 
The distribution of the maximum principal stresses before cracking and the damage pattern obtained with the vertical displacement imposed on the central column in Figure 13 for 3D idealized geometry model, in Figure 14 for the 2D idealized geometry model and in Figure 15 for the point cloud-derived 2D model. Initial cracking pattern is confirmed by all the models.

The non-linear analysis was carried out with the ENDO_ISOT_BETON constitutive law for 3D and 2D models, which takes into consideration the tensile fragile failure of the material, assigning a set of reasonable values for the material mechanical properties (Facchini et al., 2017).

The results confirm the location and the path of the first cracks to appear on the vault, when subjected to the imposed vertical displacement of the central column. At the same time, even if a good forecast can be attempted, the complete behaviour of the structure could be described only with the correct assignments assumed for all the specific properties whose influence on the results has been investigated. Specifically, it would be of major importance to determine the elastic modulus of the masonry and, in minor part, the exact thickness of the vault.

\section{CONCLUSION}

The paper presented the case study of the survey of a portion of the main building of the Forest Research Institute in Dehradun. The survey was performed as a training activity during the 'Ground Based 3D Modelling (Photogrammetry and TLS)' Tutorial, at the ISPRS TC V Mid-term Symposium, held in Dehradun, India in November 2018.

The acquired data was used for a parametric structural evaluation of the masonry vaults of the portico of the main building after imposing $10 \mathrm{~mm}$ displacement on a central column between the vaults.

The 3D geometric model of the vaults has been used in an open source finite element software to develop different numerical models of the same object. In particular an ideal geometrical model of the vaults, described by a perfectly spherical surface, was used to build two FE models employing solid (first model) and shell (second model) elements. A third model has been built directly from the $2 \mathrm{D}$ mesh derived from the point cloud data, with shell finite elements (third model). The objective of the numerical analyses was to assess both the benefits of structural meshes generated directly from point cloud data and the structural behaviour of the masonry vaults. All the models confirmed the same cracking pattern both in term of location and path of the first cracks to appear on the vaults.

\section{ACKNOWLEDGEMENTS}

The authors acknowledge the help of the co-investigators of the ISPRS project ISPRS "Education and training resources on digital photogrammetry": Prof. Anjana Vyas Faculty of Technology CEPT University (India), Dr. Vikram Sorathia Kensemble Tech Labs Gandhinagar, Gujarat (India); and acknowledge the participants in the tutorial: Mr. Sangay Gyeltshen, Ms. Nyamaa Tserendulam, Mr. Bichit Kumar Singh, Mr. Padam Bahadur Budha, Ms. Phitchayalak Wongchingchai, Ms. Saranthorn Suthana, Ms. Wanwilai Khunta, Mr. Doan Quoc Vuong, Mr. Nguyen Duc Loc, Mr. Kazi Hifajat, Mr. Sai Venkat, Mr. Sumith Satheendra, Mr. Yugandhar Kareti, Dr. Priyank Pravin Patel, Dr. Vandita Srivastava.

The authors acknowledge Dr. Prakash Chauhan (Director Indian Institute of Remote Sensing IIRS) and Dr. Sentil Kumar for support and hospitality during the Symposium.

\section{REFERENCES}

Achille, C., Fassi, F., Mandelli, A., \& Fiorillo, F. 2018. Surveying cultural heritage: summer school for conservation activities. Applied Geomatics, 10(4), 579-592. doi.org/10.1007/s12518-018-0225-3.

Balletti, C., Ballarin, M., Faccio, P., Guerra, F., Saetta, A., Vernier, P. 2018. 3D survey and 3D modelling for seismic vulnerability assessment of historical masonry buildings Applied Geomatics, $10 \quad$ (4), pp. 473-484. doi.org/10.1007/s12518-018-0214-6.

Bartoli, G., Betti, M., Biagini, P., Borghini, A., Ciavattone, A., Girardi, M., Lancioni, G., Marra, A.M., Ortolani, B., Pintucchi, B. 2017. Epistemic uncertainties in structural modelling: a blind benchmark for seismic assessment of slender masonry towers. ASCE's Journal of Performance of Constructed Facilities; 31(5), 04017067.

doi.org/10.1061/(ASCE)CF.1943-5509.0001049.

Baudin M., Dutfoy A., Iooss B., Popelin A. L., 2016 OpenTURNS: An Industrial Software for Uncertainty Quantification in Simulation, Ghanem R. et al. (eds.), Handbook of Un-certainty Quantification, Springer.

Brumana, R., Condoleo, P., Grimoldi, A., Banfi, F., Landi, A. G., Previtali, M., 2018 HR LOD based HBIM to detect influences on geometry and shape by stereotomic construction techniques of brick vaults Applied Geomatics $10 \quad 4$ doi.org/10.1007/s12518-018-0209-3.

Cardinale, T., Valva, R., \& Lucarelli, M. 2013. Advanced representation technologies applied to the temple of Neptune, the sphinx and the metope in the archaeological park of Paestum. Int. Arch. Photogramm. Remote Sens. Spatial Inf. Sci., XL-5/W1, 35-41.

doi.org/10.5194/isprsarchives-XL-5-W1-35-2013.

CloudCompare 2019. Version 2.10.2. GPL software Retrieved from http://www.cloudcompare.org/

Facchini, L., Betti, M., Corazzi, R., Kovacevic, V.C. 2017. Nonlinear seismic behavior of historical masonry towers by means of different numerical models. Proceedings of the $\mathrm{X}$ International Conference on Structural Dynamics (F. Vestroni, V. Vattulli, F. Romeo Eds.) EURODYN 2017, Roma, Italy, September 11-13, 2017. Procedia Engineering, 199, 601-606. doi.org/10.1016/j.proeng.2017.09.103.

Fiorillo, F., Fernández-Palacios, B. J., Remondino, F., \& Barba, S. 2013. 3d Surveying and modelling of the Archaeological Area of Paestum, Italy. Virtual Archaeology Review, 4(8), 5560. doi.org/10.4995/var.2013.4306.

Korumaz, M., Betti, M., Conti, A., Tucci, G., Bartoli, G., Bonora, V., Korumaz, A.G., Fiorini, L. 2017 An integrated Terrestrial Laser Scanner (TLS), Deviation Analysis (DA) and Finite Element (FE) approach for health assessment of historical structures. A minaret case study. Engineering Structures 2017; 153: 224-238. doi.org/10.1016/j.engstruct.2017.10.026.

McKay, M.D. 1992 Latin hypercube sampling as a tool in uncertainty analysis of computer models, WSC '92 Proceedings of the 24th conference on Winter simulation, Pages 557-564. doi.org/10.1145/167293.167637. 
Pieraccini, M., Betti, M., Forcellini, D., Devis, D., Papi, F., Bartoli, G., Facchini, L., Corazzi, R., Kovacevic, C.V. 2017. Radar detection of pedestrian-induced vibrations of Michelangelo's David. Plos ONE, 12(4), e0174480. doi.org/10.1371/journal.pone.0174480.

Schnabel, R., Wahl, R., Klein, R. 2007. Efficient RANSAC for Point-Cloud Shape Detection. Computer Graphics Forum, 26:2(214-226) doi.org/10.1111/j.1467-8659.2007.01016.x.

Sobol, I.M., 1993 Sensitivity Estimates for Nonlinear Mathematical Models, MMCE, Volume 1, Number 4, 407-414.

Tillotson, G. 2008. CG Blomfield: Last Architect of the Raj. South Asian Studies, 24(1), 133-139. doi.org/10.1080/02666030.2008.9628690.

Tucci, G., Conti, A., Fiorini, L. Geomatics for Knowledge and Conservation of Cultural Heritage: The Pratolino Park CaseStudy. In: Proceedings of the 1st International Congress ICONARCH," Architecture and Technology. 2012. p. 428-440.

Tucci, G., Conti, A., Fiorini, L., Panighini, F., \& Parisi, E. I. 2018a. Education and Training Resources on Digital Photogrammetry. Int. Arch. Photogramm. Remote Sens. Spatial Inf. Sci.

doi.org/10.5194/isprs-archives-XLII-5-45-2018.

Tucci, G., Conti, A., Fiorini, L., Mei, F., \& Parisi, E. I. 2018b. Digital photogrammetry as a resource for Cuban Cultural Heritage: educational experiences and community engagement within the Innova Cuba project. Int. Arch. Photogramm. Remote Sens. Spatial Inf. Sci. doi.org/10.5194/isprs-archivesXLII-5-37-2018. 